\section{Menschen helfen, Ressourcen optimieren}

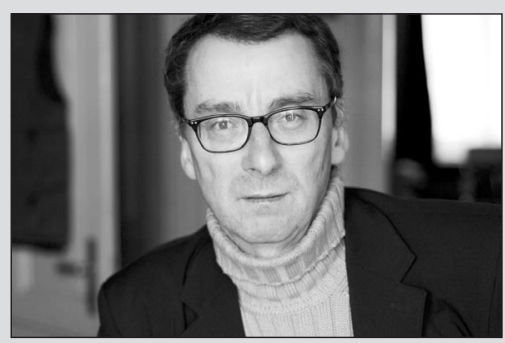

Der Einzige der stört, ist der Kunde. Die alte Erfahrung als Konsument machen auch viele Nutzer sozialer Dienste und Einrichtungen. Dabei gehört das Postulat der »Hilfe zur Selbsthilfe « zum Urbestand Sozialer Arbeit, sei sie pädagogisch (»Hilf mir, es selbst zu tun «), fortschrittlich (»Empowerment «) oder betriebswirtschaftlich (»Kundenorientierung «) ausgerichtet.

Wolf Rainer Wendt erinnert in seinem Beitrag in diesem Heft daran, dass es gute konzeptionelle Argumente für eine ernsthafte Orientierung am Nutzer sozialer Dienstleistungen gibt, denn die Eigenaktivität von Menschen in prekären Lebenslagen anzuregen, ist gerade ein konstitutives Merkmal der Sozialwirtschaft (Seite 16). Übrigens ganz im Interesse der sozialen Unternehmen selbst: In dem Maße, in dem die Ratsuchenden zum eigenen Handeln befähigt werden, lassen sich die Ressourcen der Sozialwirtschaft optimieren: »Nutzerzentrierung führt zur Prozessoptimierung. «

Evidenzbasierung und Wirkungsorientierung, Ambulantisierung und Persönliches Budget - es gibt einige Trends, die Führungskräfte veranlassen sollten, über die Nutzer-Orientierung ihrer Organisation nachzudenken. Zwei einfache Fragen als Gedankenexperiment mögen dabei helfen: Wäre ich gerne Nutzer (Klient, Patient, Ratsuchender, Angehöriger etc.) in meiner Einrichtung? Und würde ich diese auch aufsuchen, wenn es attraktive Alternativen gäbe?

Eine neue Studie des Europäischen Wirtschafts- und Sozialausschusses bestätigt die besondere Rolle der Sozialwirtschaft im wirtschaftlichen Geschehen in Europa. Peter Hermann stellt in seinem Beitrag in dieser Ausgabe die wichtigsten Ergebnisse vor (Seite 6). Verstanden wird danach die Sozialwirtschaft zwar durchaus als ein Teil der Gesamtwirtschaft. Sozialwirtschaft ist aber auch ein »Markt plus «: Marktwirtschaft und Solidarität.

Gerhard Pfannendörfer - Chefredaktion -

\section{Praxiswissen für die Sozialwirtschaft}

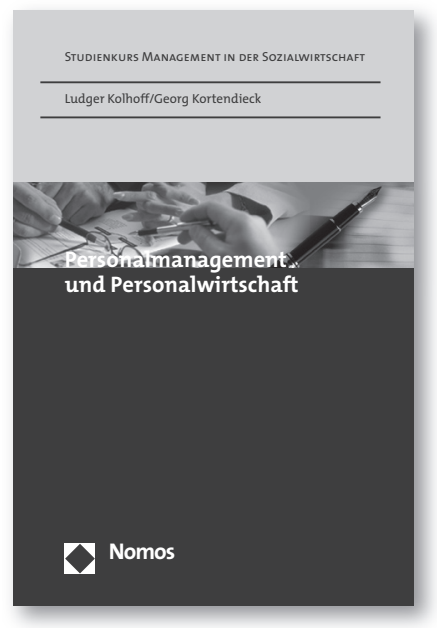

\section{Personalmanagement} und Personalwirtschaft

Von Prof. Dr. phil. Ludger Kolhoff und Prof. Dr. rer. pol. Georg Kortendieck

2006, 176 S., brosch., 19,80€, ISBN 978-3-8329-1633-6

(Studienkurs Management in der Sozialwirtschaft)

Studierende und Praktiker erhalten in dem Werk einen praxis- wie theoriegeleiteten Überblick über die wichtigsten Bereiche des Personalmanagements und der Personalwirtschaft.

Es werden die grundlegenden theoretischen Hintergründe untersucht und zentrale wie aktuelle Aspekte und Ansichten der Personalführung, Personalplanung, Personalbeschafffung, Personalhonorierung, Personalbeurteilung und auch der Personalentwicklung in der Sozialwirtschaft behandelt.

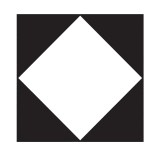

Nomos

Bitte bestellen Sie bei Ihrer Buchhandlung oder bei Nomos C07221/2104-37 | 늘 -43 www.nomos.de | sabine.horn@nomos.de 